\title{
Effect of pre-sowing treatment on seed germination of Ixora coccinea L.
}

\author{
Amruta Shivajirao Shinde*, Niranjana Sunil Chavan
}

Department of Botany, Shivaji University, Kolhapur, Maharashtra, India

Received: 06.07.2017

Accepted: 01.09.2017

Published: 26.09.2017

*Address for correspondence:

Amruta Shivajirao Shinde, Department of Botany,

Shivaji University,

Kolhapur - 416004 ,

Maharashtra, India.

E-mail: amrutashinde7730@

gmail.com

\begin{abstract}
Ixora coccinea $\mathrm{L}$. is ornamentally and medicinally important coastal plant also associated with mangroves of Sindhudurg and Ratnagiri district. In the present study, seeds of I. coccinea were treated with cold water, $50^{\circ} \mathrm{C}$ hot water, germinator solution, and also 100, 200, and 500 ppm gibberellic acid (GA). Germination percentage was measured everyday until no germination was observed. Data were analyzed using analysis of variance and the significant mean difference in pair of treatments was analyzed using $t$-test. Seeds of $I$. coccinea treated with 100 ppm GA showed highest germination percentage, i.e., $90 \%$ followed by hot water treated seeds and it showed $85 \%$ germination. Seeds were treated with GA, hot water, germinator, and soaking in cold water showed significant difference in between treatments $(P<0.05)$. Overall, the results suggest that $100 \mathrm{ppm}$ GA and hot water treatment used for enhance the germination of $I$. coccinea seeds.
\end{abstract}

KEY WORDS: Gibberellic acid, hot water treatment, Ixora coccinea, seed germination

\section{INTRODUCTION}

Ixora coccinea L. belongs to family Rubiaceae. Commonly, it is called as pendkul in Konkan region and also known as a flame of woods. Many species of Ixora are cultivated for ornamental purpose. I. coccinea L. is found in the coastal region, ghat region, and also associated with mangroves of Sindhudurg and Ratnagiri district. The flowers are scarlet red, therefore cultivated in tropical and subtropical areas for ornamental purpose (Kirtikar and Basu, 1935; Latha et al., 2001). Flowers are used in the treatment of dysentery and eruption. Roots of this plant are used to cure ulcer, fever, hiccough, and nausea (Alam, 2014). In Indian villages and tribal areas, fruits are eaten by children's, local folks, and tribes (Nazarudeen, 2010). I. coccinea L. possesses a number of medicinal properties. Flowers, leaves, stem, and roots of this plant are used in Ayurveda, in folk medicines, and in the traditional system of medicine. Regular consumption of fruits is helpful to people having problem of diabetes and obesity (Baliga and Kurian, 2012). Focusing on medicinal potential of I. coccinea, germination studies were undertaken to obtain maximum seed germination. Seeds were treated with different chemicals for various period. Treatment of distilled water, cold water, hot water, and gibberellic acid (GA) was compared for best results.

\section{MATERIALS AND METHODS}

Fruits of I. coccinea were collected from Achara, Sindhudurg district of Maharashtra. Fruits are berry type single fruit contains two seeds. Seeds are small and endospermic (Plates 1 and 2). Fruits are collected in May 2014 and weighted dried under natural sunlight. Healthy dried seeds were selected for the experiment. Healthy seeds were subjected to viability test through the floating method, in which floated seeds were considered as unviable, and the seeds were discarded. The experiment was carried out during June 2014 to December 2014 and after soaking seed germination studies were continued up to 45 days.

Experimental trials were standardized as follows:

Healthy seeds of $I$. coccinea were selected for experiment and sterilized with $0.1 \% \mathrm{HgCl}_{2}$ for $10 \mathrm{~min}$, then washed thoroughly with distilled water and treated with different treatments.

1. Soaking seeds in water for 1 and 2 days (Khosh-Khui and Kaviani, 2006)

2. Hot water treatment

3. Seeds were treated with germinator solution: $40 \%$ of germinator solution was used for the soaking, and after $6 \mathrm{~h}$, the seeds were thoroughly washed with tap water and placed for germination 


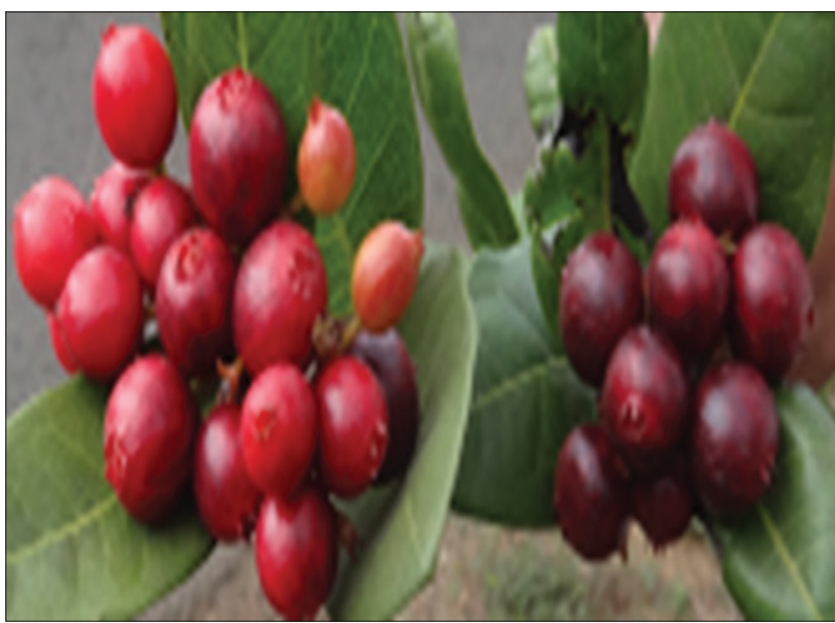

Plate 1: Fruits of Ixora coccinea L.

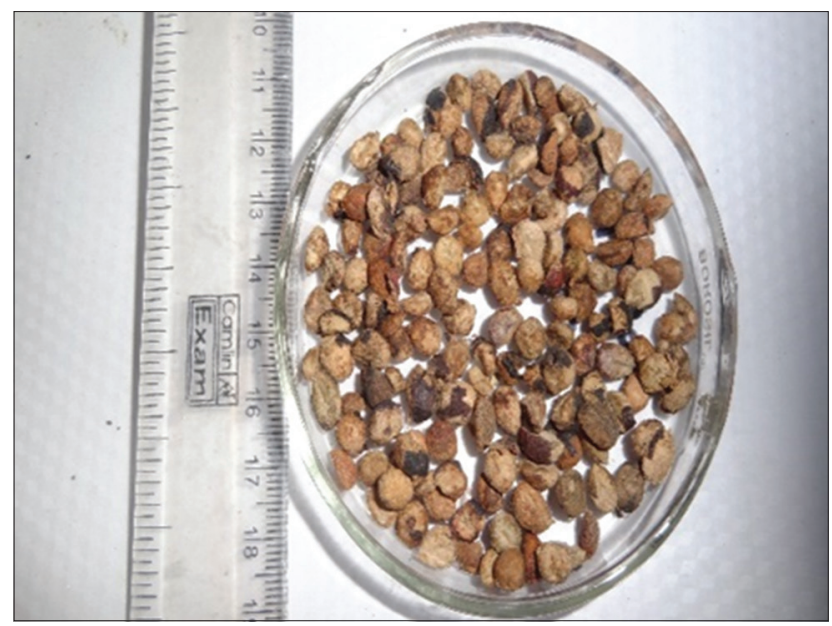

Plate 2: Seeds of Ixora coccinea L.

4. Treatment of GA (Thomas, 1994)

5. Control: Set of control seeds was maintained separately. These experiments were conducted in sterilized glass Petri plates which were filled with $10 \mathrm{~mL}$ distilled water. To avoid fungal infection, the filter paper and media were changed frequently after 1 or 2 days (Thomas, 1994), each Petri plate having 20 seeds and repeated in triplicates. A seed was considered sprouted when it discharges radical of $2 \mathrm{~mm}$ (Sayar et al., 2010). The daily observation was recorded, the results were compiled separately, and the percentage germination was calculated separately.

\section{Data Analysis}

The set of experiment was arranged in complete randomized design and consist of three replicates. The data were subjected to statistical analysis of variance (ANOVA) and $t$-test for testing significant difference in pair of treatments using Microsoft Excel. ANOVA two factors without replication were carried out to analyze the data and determine most appropriate pre-treatment method for higher germination percentage in I. coccinea seeds.

\section{RESULTS AND DISCUSSION}

\section{Germination Percentage (\%) of $I$. coccinea to Different Treatments}

Seeds of $I$. coccinea treated with germinator solution, hot water treatment 1 day, 2 days soaked in cold water, and germination percentage were represented in Figure 1.

ANOVA was done from the values of Figure 1 using Microsoft Excel. The obtained values of $F$ statistics as $F$ $3,6=22.45$. Calculated $F$ is $22.45 \geq$ table $F 3.15$ and $P$ value is smaller than 0.05 and also for a number of days $F$ statistics as $F 3,6=7.40$ and calculated $F$ is $7.40 \geq 2.66$ table $F$ and $P$ value is smaller than 0.05 , this rejects the null hypothesis. $\mathrm{H}_{0}$ :There is significant difference in treatment effects. $t$-test was done for testing significant difference in pair of treatments in between control to germinator and hot water for testing range of higher germination. Absolute ltl $=-4.519$ is greater than critical value 2.44, and also $P$ value is smaller than 0.05 , so there is significant difference between germinator and control. $\mathrm{Ltl}=-4.803$ is greater than critical value 2.44 , and also $P$ value is smaller than 0.05 , so there is significant difference between hot water and control. The average values of control 26.67, germinator 36.67 , and hot water 45.71. From the above values, it is concluded that hot water treated seeds showed higher germination percentage.

Seeds of $I$. coccinea soaked in germinator showed early germination as compared to other treatments and control. Hot water treated seeds showed germination after 14 days and also showed higher germination percentage after 45 days (85\%). Seeds of Ixora treated with germinator solution germinate after 9 days and $70 \%$ germination after 45 days. Seed germination under different soaking period gave fair germination percentage (35\%), this was not significant within the treatments. 1 and 2 days soaking in water treatment showed lower germination percentage than control, these results were similar to pre-treatment to Afzelia africana seeds (Amusa, 2011), and control treatment showed higher germination percentage because over soaking seeds of Jubaeopsis caffra in water reduce germination through oxygen deficiency (Robertson and Small, 1977). However, Owonubi et al. (2005) suggested that seeds of Azadirachta indica soaked in cold water for 1 and $12 \mathrm{~h}$ showed an increasing rate of seed germination. 


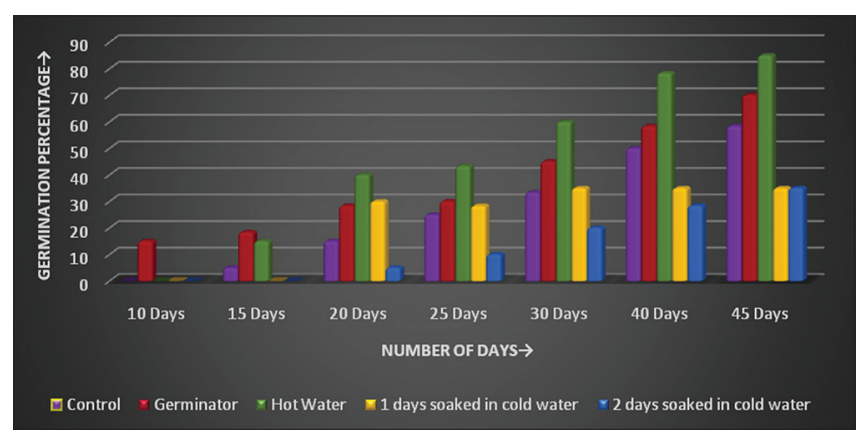

Figure 1: Germination percentage of seeds of Ixora coccinea L. to different treatments

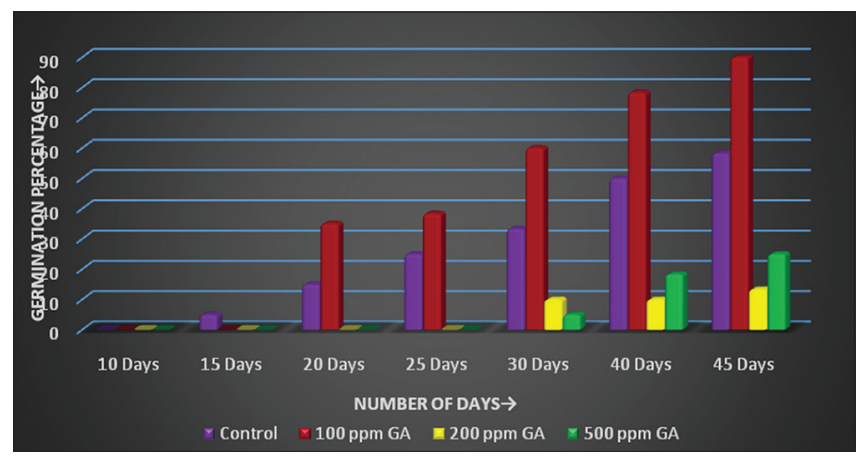

Figure 2: Germination percentage of seeds of Ixora coccinea treated with gibberellic acid

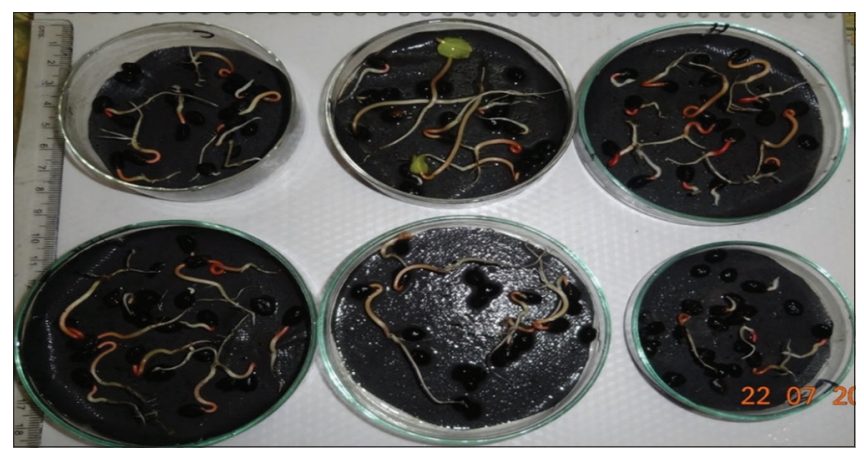

Plate 3: Germination percentage of Ixora coccinea to different treatments, (1) Control, (2) germinator, (3) hot water treatment, (4) 100 ppm, (5) 1 day soaked in water, (6) 2 days soaked in water

Okonwu and Eboh (2017) reported that $C$. verrucosa seeds treated with $\mathrm{HCl}$, sodium nitrate, and hot water showed higher germination percentage as compared to control. Usman et al. (2010) reported that seeds Acacia senegal treated with hot water for $10 \mathrm{~min}$ showed best results in higher germination percentage. Sanyang et al. (2008) concluded that seeds of $A$. senegal treated with hot water for 10 min showed early germination. Seeds of Albizia julibrissin treated with hot water, soaking in warm water at $40^{\circ} \mathrm{C}$ and $50^{\circ} \mathrm{C}$, and soaking period were 1-6 h. Seeds soaking in $40^{\circ} \mathrm{C}$ and $50^{\circ} \mathrm{C}$ showed $86-91 \%$ germination (Merou, 2011). Ixora seeds treated with hot water and showed $85 \%$ germination, this result close to Albizia results.
ANOVA was done from the values of Figure 2 using Microsoft Excel. The obtained values of $F$ statistics as $F 3$, $6=16.99$. Calculated $F$ is $16.99 \geq$ table $F 3.28$ and $P$ value is smaller than 0.05 and calculated $F$ is greater than table $F$, so again, here rejected the null hypothesis. There is significant difference in treatments. By applying, $t$-test for testing significant difference in pair of treatments. $\mathrm{Ltl}=-3.469$ is greater than critical value 2.57 and $P$ value is smaller than 0.05 . Therefore, from average values, it is said that $100 \mathrm{ppm}$ GA showed higher germination percentage.

Seeds of I. coccinea treated with GA start germination after 19 days, but untreated seeds showed early germination and started germination after $14^{\text {th }}$ days. $100 \mathrm{ppm}$ GA treated seeds showed higher germination percentage, and it was 90\% (Figure 2). Seeds treated with $200 \mathrm{ppm}$ GA showed lower germination percentage $13.33 \%$ as compared to control (Plate 3). Singh and Murthy (1987) reported that GA at higher concentration increases germination percentage in of Cassia obtusifolia. Gunasekarn et al. (2001) concluded that 100 ppm GA showed higher germination of nutmeg, these results tandem with present investigation. GA plays an important role to stimulate germination and lower down the difference in onset and final germination which promote to increase the hydrolytic activity (Joshi and Dhar, 2003; Manjkhola et al., 2003). Shivanna et al. (2007) have noticed that GA and indole-3acetic acid showed higher germination. In process of seed germination, gibberellins are played an important role to stimulate the growth of embryo (Hedden, 2017).

\section{CONCLUSION}

The best method for I. coccinea seed germination is $100 \mathrm{ppm}$ GA. The maximum percentage was obtained in the treatment of hot water and germinator solution. However, among all the methods, 100 ppm GA and hot water treatment are found to be suitable for I. coccinea seeds for better results with maximum germination. For mass propagation and conservation point of view, hot water treatment is more suitable. Furthermore, without any chemicals, the plantlets of Ixora can be raised and domesticated. Thus, the eco-friendly protocol has been developed for I. coccinea.

\section{REFERENCES}

Alam MK. Medical etanobotany of the Marma tribe of Bangladesh. Econ Bot 2014;46:330-5.

Amusa TO. Effects of three pre-treatment techniques on dormancy and germination of seeds of Afzelia africana ( $\mathrm{Sm}$. Ex pers). J Hortic Forestry 2011;3:96-103. 
Baliga MS, Kurian PJ. Ixora coccinea Linn.: Traditional uses, phytochemistry and pharmacology. Chin J Integr Med 2012;18:72-9.

Gunasekarn M, Prasath D, Krishnasamy V. Effect of chemical treatment on germination of nutmeg (Myristica fragrans Houtt.) seeds. J Species Aromat Crops 2001;10:57-8.

Hedden P. Gibberellins reference module in life sciences. Encyclopedia Appl Plant Sci Second Ed 2017;1:411-20.

Joshi M, Dhar U. Effect of various pre-sowing treatments on seed germination of Haracleum candicans Wall. ex. Dc: A high value medicinal plant. Seed Sci Technol 2003;31:737-43.

Khosh-Khui M, Kaviani K. Investigation and a sexual propagation of chin berry (Melia azedarach L.). J Plant Sci 2006;1:31-5.

Kirtikar KR, Basu BD. Indian Medicinal Plants. Allahabad, India: Lalit Mohan Basu; 1935.

Latha PG, Panikkar KR, Suja SR, Abraham A, Rajasekharan S. Chemistry, pharmacognosy, pharmacology and botany of Ixora coccinea - A review. J Med Aromat Plant Sci 2001;23:670-6.

Manjkhola S, Dhar U, Rawal R. Treatments to improve seed germination in Arnebia benthami: An endangered medicinal herb of high altitude Himalaya. Seed SciTechnol 2003;31:571-7.

Merou T, Takos I, Konstantinidou E, Galatsidas S, Varsamis G. Effect of different pre-treatment methods on germination of Albizia julibrissin seeds. Seed SciTechnol 2011;39:248-52.

Nazarudeen A. Nutritional composition of some lesser known fruits used by the ethnic communities and local folks of Kerala. Indian J Tradit Knowl 2010;9:398-402.

Okonwu K, Eboh IG. Effects of Seed treatment on the germination of Crotalaria verrucosa L. Int J Appl Life Sci 2017;10:1-8.
Owonubi JJ, Otegbeye GO, Nwokedi C. Development of pregermination technique for Azadirachta indica: Preliminary investigation. In: Popoola L, Mfon P, Oni PI, editors. Sustainable Forest Management in Nigeria: Lessons and Prospects (Proceedings of the $30^{\text {th }}$ Annual Conference of the Forestry Association of Nigeria, Held in Kaduna, Kaduna State; 2005. p. 29-38.

Robertson BI, Small JG. Germination of Jubaeopsis caffra seeds. Principles 1977;21:114-22.

Sanyang SE, Kabura BH, Huang WC. Effects of some seed pretreatments on emergence of Acacia senegal (L.). World J Agric Sci 2008;4:213-9.

Sayar R, Bchini H, Mosbahi M, Khemira H. Response of Durum wheat (Triticum durum Dest) growth to salt and drought stresses. Czech J Genet Plant Breed 2010;2:54-63.

Shivanna H, Balachandra HC, Suresha L. Influence of growth regulators and pre-sowing chemicals on germination and growth parameters of Prosopis cineraria (L) Druce. Karnataka J Agric Sci 2007;20:328-9.

Singh C, Murthy YS. Effect of some growth regulators on the seed germination and seedling growth of Cassia obtusifolia. Acta Bot Indica 1987;15:17-79.

Thomas G. A Study on Germination, Growth and Metabolism of Cassia sophera L. and on the Rooting of Spilanthes Ciliate H. B. K.: Two Medicinal Plants, Ph.D. Thesis Submitted to Faculty of Sciences. Kottayam: Mahatma Gandhi University; 1994.

Usman A, Sotannde OA, Mbaya YP, Musa Y. Effects of hot and cold water pre-treatments on emergence of Acacia senegal seeds in the nursery. J Res Forestry Wildl Environ 2010;2:207-13. 